\title{
Australian experience of peptide receptor radionuclide therapy in lung neuroendocrine tumours
}

\author{
Lisi Elizabeth Lim ${ }^{1}$, David L. Chan ${ }^{2,3}$, David Thomas ${ }^{4}, Y_{a n g} \mathbf{D u}^{5}$, Gary Tincknell ${ }^{4}$, Anna \\ Kuchel $^{6,7}$, Alexander Davis ${ }^{2}$, Dale L. Bailey ${ }^{2,8}$, Nick Pavlakis'2,8,9, Gabrielle Cehic ${ }^{5,10}$, \\ William Macdonald ${ }^{11}$, David Wyld ${ }^{6,7}$ and Eva Segelov ${ }^{1,12}$ \\ ${ }^{1}$ Department of Medical Oncology, Monash Health, Melbourne, Australia \\ ${ }^{2}$ Department of Medical Oncology, Royal North Shore Hospital, Sydney, Australia \\ ${ }^{3}$ Bill Walsh Translational Cancer Research Laboratory, Kolling Institute, University of Sydney, Sydney, Australia \\ ${ }^{4}$ Department of Medical Oncology, St. George Hospital, Sydney, Australia \\ ${ }^{5}$ Department of Nuclear Medicine, The Queen Elizabeth Hospital, Adelaide, Australia \\ ${ }^{6}$ Department of Medical Oncology, Royal Brisbane and Women's Hospital, Brisbane, Australia \\ ${ }^{7}$ Faculty of Medicine, University of Queensland, Brisbane, Australia \\ ${ }^{8}$ Sydney Vital Translational Cancer Research Centre, Royal North Shore Hospital, Sydney, Australia \\ ${ }^{9}$ Faculty of Medicine and Health, University of Sydney, Sydney, Australia \\ ${ }^{10}$ University of South Australia, Adelaide, Australia \\ ${ }^{11}$ Department of Nuclear Medicine, Fiona Stanley Hospital, Perth, Australia \\ ${ }^{12}$ Faculty of Medicine, Monash University, Melbourne, Australia \\ Correspondence to: Lisi Elizabeth Lim, email: elizabeth.lisi.lim@gmail.com
}

Keywords: lung; carcinoid; atypical; neuroendocrine; peptide receptor radionuclide therapy

Received: May 09, $2020 \quad$ Accepted: June 15, $2020 \quad$ Published: July 07, 2020

Copyright: Lim et al. This is an open-access article distributed under the terms of the Creative Commons Attribution License 3.0 (CC BY 3.0), which permits unrestricted use, distribution, and reproduction in any medium, provided the original author and source are credited.

\section{ABSTRACT}

Background: Peptide receptor radionuclide therapy (PRRT) is an approved treatment modality for gastroenteropancreatic neuroendocrine tumours (GEP NETs), Although Phase III randomised clinical trial data is not available for NETs of other site of origin, in practice, PRRT is used more widely in clinical practice, based on its mechanism of targeting the somatostatin receptor. Use of PRRT for lung (bronchial) NET, specifically typical and atypical carcinoid (TC, AC), has been reported only in small retrospective case series. This multicentre study adds to the evidence regarding utility of PRRT for lung NETs.

Materials and Methods: A retrospective chart review of patients with TC and AC who received ${ }^{177} \mathrm{Lu}$-dotatate PRRT between January 2002 and June 2019 in six hospitals across Australia was undertaken. Data regarding demographics, efficacy and toxicity was evaluated at each site by the treating clinician.

Results: Forty-eight patients (32 AC, 15 TC, 1 unclassified) received a median of four ${ }^{177} \mathrm{Lu}$-dotatate treatments. There was a median of one prior line of systemic treatment (range: $0-3$ ). The response rate to ${ }^{177} \mathrm{Lu}$-dotatate was $33 \%$, with a median overall survival of 49 months (range of 3-91), at a median follow up of 33 months. This compares favourably with GEP NET. Overall toxicity was recorded as modest.

Conclusions: ${ }^{177}$ Lu-dotatate PRRT in patients with lung NETs is used in real world practice, where it appears well-tolerated with some efficacy. Further evidence could be obtained through a global prospective clinical or registry trial. 


\section{INTRODUCTION}

Neuroendocrine tumours (NETs) are uncommon malignancies, comprising $0.5 \%$ of all cancers $[1,2]$. This widely heterogenous group of malignancies arise from neuroendocrine cells that are found in nearly every organ. The gastrointestinal tract is the most common primary site, accounting for around $65 \%$ of all NETs, but this includes many small tumours found incidentally on imaging or endoscopy. Lung is the primary site for approximately $20-25 \%$ of NETs [3]; conversely NETs comprises about $2 \%$ of all lung malignancies [4]. In an Australian series, lung NETs comprised $19 \%$ of all NETs (including appendiceal) diagnosed over a 30 year period [5].

Pathological classification of lung (bronchial) NETs continues with the nomenclature of typical carcinoid (TC) and atypical carcinoid (AC), although there is rationale to move to a unified nomenclature shared by NET from all origins $[6,7]$. The American Joint Committee on Cancer/World Health Organisation (AJCC/WHO) classification uses the collective term neuroendocrine neoplasms (NENs), with subcategories NET (Grade 1-2) and neuroendocrine carcinoma (Grade 3) [8]. Poorly differentiated and large cell neuroendocrine carcinomas (NECs) are considered to be separate entities and treated differently.

Metastatic and locally advanced lung NETs, whilst rare tumours, cause significant morbidity and mortality $[1,2,9]$. Treatment options are limited both in levels of evidence and access (including funding) and are often extrapolated from therapies tested in patients with gastroenteropancreatic (GEP) NETs. Randomised controlled trial evidence has been sparse until recently, where the number of trials has expanded. New trials have demonstrated that adequate numbers of patients can be recruited through global collaborations, both for protocols specific to lung NETs and those recruiting patients with NETs from a variety of sites.

Systemic therapy is the mainstay of treatment for advanced lung NETs, though there is no univocal treatment strategy [10]. NETs as a whole are less responsive to chemotherapy, with limited efficacy and further evaluation needed for drugs including temozolomide, capecitabine, 5-fluorouracil, doxorubicin, etoposide and platinum agents $[10,11]$. Somatostatin analogues (SSA) are commonly used for advanced lung NETs, without specific evidence until very recently, with publication of the LUNA trial [12]. This phase II study randomised patients with lung and thymic NETs to receive long acting pasireotide, everolimus, or a combination of both agents, and showed a 39.0\% disease control rate with pasireotide alone (95\% confidence interval (CI): $24.2-$ $55.5)), 33.3 \%$ for everolimus alone and $58.5 \%$ for the combination. Everolimus was also shown to have efficacy among patients with lung NETs enrolled in the phase III RADIANT-4 trial $[13,14]$.
Peptide receptor radionuclide therapy (PRRT) is a targeted systemic therapy where a radionuclidesomatostatin analogue complex is delivered to NET cells via cell surface somatostatin receptors (SSTR). Various radionuclides have been used, including the beta emitters Yttrium-90 $\left({ }^{90} \mathrm{Y}\right)$ and Lutetium-177 $\left({ }^{177} \mathrm{Lu}\right)$, with novel alpha emitters now also under investigation. PRRT is a firmly established treatment modality for advanced GEP NETs following the publication of the landmark NETTER-1 trial $[15,16]$, where patients with progressive midgut NET were randomised to receive ${ }^{177} \mathrm{Lu}$-dotatate with ongoing octreotide long-acting repeatable (LAR) therapy, or high dose octreotide LAR alone. The primary endpoint of progression free survival (PFS) was strongly in favour of PRRT, with a hazard ratio (HR) of 0.21 (95\% CI: $0.14-0.33 ; p<0.0001)$. Median overall survival was 27.4 months in the group treated with high-dose octreotide LAR and had not been reached in the PRRT arm at last study update [16]. There was an acceptable toxicity profile and a positive impact on quality of life (QOL) [16, 17].

The significant benefit for PRRT in midgut NETs has provoked debate about whether randomised trials are required to prove its efficacy in NETs of other site of origin. Unlike GEP NETs, which reliably express SSTR, the expression of STTR in lung NETs varies $[18,19]$, although this was demonstrated with immunohistochemistry, which has variable validity and does not always correlate with SSTR-positron emission tomography findings. There was no identified relationship with tumour aggressiveness or functional status and no difference in SSTR expression has been seen between AC and TC [19].

Several small retrospective case series $(n=22-34)$ of patients with lung NETs have reported potential benefit from PRRT [20-23]. Response rates and outcomes have varied, as expected with heterogenous populations and retrospective, uncontrolled response review. Larger series using various isotopes have also been reported; the largest demonstrated benefit in 114 patients treated with radiopeptides containing ${ }^{90} \mathrm{Y},{ }^{177} \mathrm{Lu}$ or a combination in 45 , 48, and 21 patients respectively [24].

NET consensus guidelines either omit specific comment on the use of PRRT in lung NETs [25], or state that imaging with SSTR-PET can assist in identifying patients who may benefit from PRRT [26, 27]. Current National Comprehensive Cancer Network (NCCN) guidelines propose that PRRT should be considered for patients with lung NETs following progression on SSA, if SSTR positive on imaging $[28,29]$. The Commonwealth Neuroendocrine Tumour Collaboration (CommNETs) and North American Neuroendocrine Tumor Society (NANETS) Consensus for Lung Neuroendocrine Tumors (LNET) also recommend that PRRT may be an option in patients with SSTR positive tumors, based on international expert opinion [30].

For subtypes of rare diseases, such as lung NETs, retrospective case series remain important for 
documenting treatment benefits and risks. Due to reimbursement restrictions, PRRT is used in only a limited number of centres in Australia, so that collecting data from such centres provides a picture of real world use. We therefore undertook a retrospective review of patients with lung NETs (AC and TC) treated with ${ }^{177} \mathrm{Lu}$-dotatate in Australian centres.

\section{RESULTS}

Forty-eight patients were identified, of which 30 were male. Median age was 68 years (range: $22-81$ years). Patient demographics and tumour characteristics are shown in Table 1.

Thirty-two patients received PRRT for progressive disease; nine patients were treated only for symptom control; seven patients received treatment for both progression and symptoms. One patient who had progessive disease received PRRT plus capecitabine chemotherapy as a neoadjuvant approach prior to curative intent surgery. 42 patients were treated with one single course of PRRT, four had 2 and two had 3 courses. Patients received a median of four doses per course of PRRT (range: 1-10), with one patient who received 10 doses as a single drawn out course of PRRT. The median cumulative radiation dose administered per patient, including that from subsequent courses of PRRT, was $31.9 \mathrm{GBq}$ (range: 7.6-49.7GBq).

The median time from diagnosis to first PRRT was 15.5 months (range: 1-206 months). Patients received a median of one prior line of systemic treatment (range: 0-3), prior to PRRT. 31 patients were treated with first line SSA, with a median duration of first line SSA of 18 months (range: 1-52 months). Six patients received PRRT as first line systemic treatment.

Twenty-three patients received systemic therapy during PRRT: 11 received concurrent SSA; eight received concurrent capecitabine chemotherapy and four received concurrent combination capecitabine and temozolomide chemotherapy. Regarding SSA therapy, 36 patients received SSA before PRRT while eight received SSA prior to and continued during PRRT. Three patients were recommenced on SSA only during PRRT.

Median follow-up from delivery of the first PRRT dose was 33 months for the entire cohort. Median overall survival was 49 months (OS range: 3-91 months; Figure 1).

Overall response rate was 33\% (16 patients), with all responses documented as partial. Stable disease was described in 24 patients, yielding a disease control rate of $83 \%$. Eight patients $(17 \%)$ were deemed to have progressive disease as best response. Details of the 16 responders are summarised in Table 2.

Two responders were rechallenged with further PRRT as the next line of systemic treatment 36 months post the first course of PRRT, with stable disease as best response. Median overall survival for all responders was 43 months (OS range: 9-91 months; Table 2). Only three of the 13 responders who were alive at data cut-off required further systemic treatment.

With regard to symptoms, post-PPRT there was documented improvement in 14 of 30 patients with secretory symptoms that included flushing and diarrhoea. Fifteen of 33 patients with non-secretory symptoms, including pain and dyspnoea, had documented benefit. No patient experienced an exacerbation of secretory or nonsecretory symptoms.

Patients received up to four further lines of systemic treatment after the initial course of PRRT. Twenty-nine patients did not receive any further therapy; respectively, 13, 3, 2 and 1 patient received one, two, three and four further lines; none received more than four. Of the 29 patients who received no further treatment, inclusive of SSA, this was due to ongoing control of disease in the majority (20 patients). Of the six patients who were retreated with subsequent courses of PRRT, two were documented to have a partial response, while the others had stable disease as best response.

\section{Adverse events}

The main toxicities from PRRT included five serious adverse events with two deaths (Table 3).

Regarding serious toxicity, one patient who had been heavily pretreated developed acute myeloid leukemia (AML), diagnosed at the time of her first PRRT course, post her second PRRT dose. The AML led to subsequent death. This patient had previously received alkylating chemotherapy (streptozotocin) and 5-fluorouracil, and multiple course of radiotherapy. The development of AML occurred eight to ten weeks post PRRT commencement and approximately four years post streptozotocin.

One death was recorded in a second patient who developed AML. This 81 year old patient, initially developed myelodysplastic syndrome (MDS) 48 months post PRRT, which transformed to lethal AML a year after MDS development. This patient had a normal blood film at PRRT commencement, and received four doses of PRRT with a cumulative dose of $29.35 \mathrm{GBq}$, concurrent with infusional 5-fluorouracil. Prior treatment consisted of SSA only, and cytogenetics were suggestive of therapy related AML.

Acute kidney injury was documented in one patient. This occured during the first PRRT treatment, in the context of carcinoid syndrome with severe diarrhoea resulting in volume depletion. The patient required inpatient admission for intravenous fluids, but recovered fully and proceeded to further PRRT without toxicity. The only serious gastrointestinal adverse event consituted grade 3 nausea which occurred after the first PRRT dose in a single patient who required hospital admission for antiemetics. There was no recurrence with use of prophylactic anti-emetics in subsequent PRRT doses. 


\begin{tabular}{|c|c|}
\hline & $\begin{array}{l}\text { Cohort } \\
(n=48)\end{array}$ \\
\hline $\begin{array}{l}\text { Age } \\
<70 \\
\geq 70\end{array}$ & $\begin{array}{l}28 \\
20\end{array}$ \\
\hline $\begin{array}{l}\text { Histopathology } \\
\text { Typical carcinoid } \\
\text { Atypical carcinoid } \\
\text { Unknown }^{*}\end{array}$ & $\begin{array}{c}15 \\
32 \\
1\end{array}$ \\
\hline $\begin{array}{l}\text { Ki67\% } \\
<3 \\
3-20 \\
\text { Unknown }\end{array}$ & $\begin{array}{c}15 \\
31 \\
2\end{array}$ \\
\hline $\begin{array}{l}\text { Sites of disease } \text { e }^{* *} \\
\text { Liver } \\
\text { Bone } \\
\text { Lymph nodes } \\
\text { Lung } \\
\text { Subcutaneous } \\
\text { Pleura } \\
\text { Brain } \\
\text { Adrenal } \\
\text { Other (breast, gallbladder, ovary, thyroid) }\end{array}$ & $\begin{array}{c}37 \\
36 \\
29 \\
13 \\
3 \\
3 \\
3 \\
2 \\
5\end{array}$ \\
\hline $\begin{array}{l}\text { Prior lines of systemic treatment } \\
0 \\
1 \\
2 \\
\geq 3\end{array}$ & $\begin{array}{c}\text { patients } \\
7 \\
32 \\
7 \\
2\end{array}$ \\
\hline $\begin{array}{l}\text { Chromogranin } A\left(x U L N^{\wedge}\right) \\
<2 \\
\geq 2 \\
\text { Unknown }\end{array}$ & $\begin{array}{c}\text { patients } \\
15 \\
30 \\
3\end{array}$ \\
\hline $\begin{array}{l}\text { Symptomatic } \\
\text { Yes } \\
\quad \text { Secretory symptoms } \\
\quad \text { Non-secretory symptoms }\end{array}$ & $\begin{array}{c}\text { patients } \\
42 \\
30 \\
33\end{array}$ \\
\hline $\begin{array}{l}\text { No. of PRRT courses } \\
1 \\
2 \\
3\end{array}$ & $\begin{array}{c}\text { patients } \\
42 \\
4 \\
2\end{array}$ \\
\hline $\begin{array}{l}\text { No. of PRRT doses per course } \\
\leq 2 \\
3 \\
4 \\
5 \\
6 \\
\geq 7\end{array}$ & $\begin{array}{c}\text { patients } \\
4 \\
2 \\
33 \\
1 \\
5 \\
3\end{array}$ \\
\hline
\end{tabular}

"no accessible histopathology(overseas sample). ${ }^{* *}$ multiple sites documented where applicable. ${ }^{\wedge} \boldsymbol{x} \boldsymbol{U} \boldsymbol{N}=$ multiples of Upper Limit of Normal in local laboratory.

The remaining serious adverse event was the development of superior vena caval obstruction from a thrombus that developed during a course of PRRT. The treatment could not be retrospectively excluded as a contributing factor.

\section{DISCUSSION}

This study represents the largest case series of patients with $\mathrm{TC}$ and $\mathrm{AC}$ treated with ${ }^{177} \mathrm{Lu}$-dotatate thus contributing to the real world evidence base. For patients with uncommon cancers, especially where treatment options are limited, documenting treatment benefit and toxicity is an important contribution to the knowledge base. Previous reports of the use of PRRT in lung NETs consist of retrospective case series, summarised in Table 4.

PRRT is only available at limited centres in Australia, due to Government health reimbursement arrangements. Hence the experience reported here, in six centres across most of the states of Australia, is a reasonable representation of patients with lung NET in the community. 
Table 2: Details of responders to PRRT

\begin{tabular}{cccc}
\hline Patient no. & $\begin{array}{c}\text { Months to first systemic treatment post } \\
\text { PRRT }\end{array}$ & Status & $\begin{array}{c}\text { Months of follow up from 1st } \\
\text { PRRT dose }\end{array}$ \\
\hline $\mathbf{1}$ & - & Alive & 43 \\
$\mathbf{2}$ & - & Deceased & 19 \\
$\mathbf{3}$ & - & Alive & 6 \\
$\mathbf{4}$ & - & Alive & 9 \\
$\mathbf{5}$ & - & Deceased & 33 \\
$\mathbf{6}$ & 24 & Alive & 63 \\
$\mathbf{7}$ & - & Alive & 8 \\
$\mathbf{8}$ & - & Alive & 11 \\
$\mathbf{9}$ & - & Alive & 43 \\
$\mathbf{1 0}$ & 36 & Deceased & 45 \\
$\mathbf{1 1}$ & - & Alive & 41 \\
$\mathbf{1 2}$ & 36 & Alive & 49 \\
$\mathbf{1 3}$ & 36 & Alive & 91 \\
$\mathbf{1 4}$ & - & Alive & 52 \\
$\mathbf{1 5}$ & - & Alive & 76 \\
$\mathbf{1 6}$ & 8 & Alive & 68 \\
\hline
\end{tabular}

Response rates and median overall survival in our cohort are consistent with the largest study of PRRT in lung NET, where 114 patients with bronchial NET were treated with various isotopes $\left({ }^{90} \mathrm{Y},{ }^{177} \mathrm{Lu},{ }^{90} \mathrm{Y}+{ }^{177} \mathrm{Lu}\right)[24]$. Mariniello et al. reported for this series a median overall survival of 58.8 months and objective response rates of $26.5 \%$. Toxicity was also comparable, with good tolerance for PRRT, however, notably the restrospective Mariniello series had no cases of myelodysplasia or leukemia, at comparable median follow up of 45.1 months (range 2-191 months). In addition, the most significant renal toxicity was grade 2 and occurred more commonly with ${ }^{90} \mathrm{Y}$.

Results from a large single centre study using data from the Netherlands Cancer Registry revealed a 4\%

\section{Overall survival}

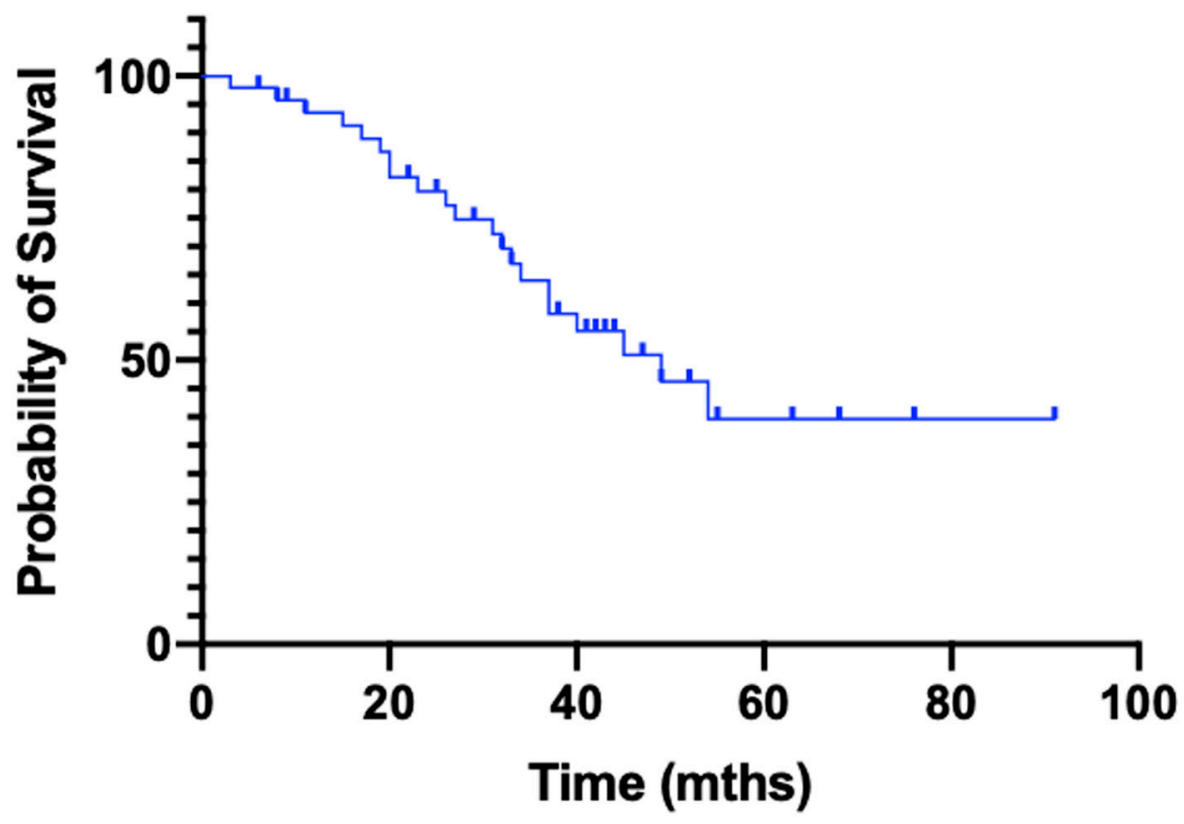

Figure 1: Kaplan-Meier curve of overall survival. 
Table 3: PRRT toxicity

\begin{tabular}{lccc}
\hline Toxicity & $\begin{array}{c}\text { Any grade } \\
\text { (number of } \\
\text { patients) }\end{array}$ & $\begin{array}{c}\text { Grade }^{*} \\
\mathbf{1 - 2}\end{array}$ & Grade 3-5 $^{-2}$ \\
\hline Haematological & 16 & 13 & 2 \\
Renal & 5 & 4 & 1 \\
Intestinal & 6 & 5 & 1 \\
Hepatic & 2 & 2 & 0 \\
Other (Superior vena cava obstruction) & 1 & 0 & 1 \\
\hline
\end{tabular}

${ }^{*}$ CTCAE grading version 4.0; toxicity at any stage during PRRT.

Table 4: Prior studies of PRRT including patients with lung or bronchial NET ${ }^{*}$

\begin{tabular}{|c|c|c|c|c|c|c|c|}
\hline Study & $n$ (LNETs) & $\begin{array}{c}n \text { (other } \\
\text { NETs) }\end{array}$ & Isotope & Median OS & Median PFS & $\begin{array}{l}\text { Median } \\
\text { TTP }\end{array}$ & ORR \\
\hline Mariniello A, 2016 [24] & 114 & - & $\begin{array}{c}{ }^{90} \mathrm{Y} \\
\mathrm{v}^{177} \mathrm{Lu} \\
\mathrm{v} \\
{ }^{90} \mathrm{Y}+{ }^{177} \mathrm{Lu}\end{array}$ & $58.8 \mathrm{~m}$ & $28.0 \mathrm{~m}$ & - & $\begin{array}{c}\text { Highest with }{ }^{77} \mathrm{Lu} \text { at } \\
38.1 \%\end{array}$ \\
\hline Brabander T, 2017 [31] & 23 & 420 & ${ }^{177} \mathrm{Lu}$ & $63 \mathrm{~m}$ & $29 \mathrm{~m}$ & - & $39 \%$ \\
\hline $\begin{array}{l}\text { Horsch D, } 2016 \text { [32] } \\
\text { (German registry) }\end{array}$ & 18 & 396 & $\begin{array}{c}{ }^{90} \mathrm{Y} \\
\mathrm{v}^{177} \mathrm{Lu} \\
\mathrm{v} \\
{ }^{90} \mathrm{Y}+{ }^{177} \mathrm{Lu}\end{array}$ & $59 \mathrm{~m}$ & $41 \mathrm{~m}$ & - & $28 \%$ \\
\hline Parghane RV, 2017 [21] & 22 & - & ${ }^{177} \mathrm{Lu}$ & $40 \mathrm{~m}$ & & - & $\begin{array}{c}63 \% \\
\text { (3 scale criteria) }\end{array}$ \\
\hline Demirci E, 2019 [33] & 29 & 157 & ${ }^{177} \mathrm{Lu}$ & - & $36.4 \mathrm{~m}$ & - & $50 \%$ \\
\hline van Essen M, 2007 [34] & 9 & 7 & ${ }^{177} \mathrm{Lu}$ & - & - & $31 \mathrm{~m}$ & $50 \%$ \\
\hline Sabet, 2017 [22] & 22 & - & ${ }^{177} \mathrm{Lu}$ & $42 \mathrm{~m}$ & $27 \mathrm{~m}$ & - & $27.3 \%$ \\
\hline Imhof, 2011 [35] & 84 & 1109 & ${ }^{90} \mathrm{Y}$ & - & - & - & $29.7 \%$ \\
\hline Villard, 2012 [36] & $\mathrm{N} / \mathrm{E}$ & 486 & $\begin{array}{c}{ }^{90} \mathrm{Y} \\
\mathrm{v} \\
{ }^{90} \mathrm{Y}+{ }^{177} \mathrm{Lu}\end{array}$ & $\begin{array}{r}47.5 \mathrm{v} \\
66.1 \mathrm{~m}\end{array}$ & - & - & - \\
\hline Gabriel, 2019 [36] & 4 & 34 & ${ }^{90} \mathrm{Y}$ & $79 \mathrm{~m}$ & - & - & - \\
\hline Garske-Roman, 2018 [37] & 6 & 200 & ${ }^{177} \mathrm{Lu}$ & $43 \mathrm{~m}$ & $27 \mathrm{~m}$ & - & $24 \%$ \\
\hline Baum, 2018 [38] & 75 & 1048 & $\begin{array}{c}{ }^{90} \mathrm{Y} \\
\mathrm{v}^{177} \mathrm{Lu} \\
\mathrm{v} \\
{ }^{90} \mathrm{Y}+{ }^{177} \mathrm{Lu}\end{array}$ & $\begin{array}{c}40 \mathrm{~m} \\
\text { (LNETs) }\end{array}$ & $\begin{array}{c}11 \mathrm{~m} \\
\text { (LNETs) }\end{array}$ & - & - \\
\hline Sharma, 2017 [39] & 18 & 135 & $\begin{array}{l}{ }^{90} \mathrm{Y} \\
{ }^{177} \mathrm{Lu}\end{array}$ & - & - & $\begin{array}{c}18.6 \mathrm{~m} \\
\text { (LNETs) }\end{array}$ & - \\
\hline $\begin{array}{l}\text { Koffas, } 2016[40] \\
\text { (abstract) }\end{array}$ & 22 & - & $\begin{array}{l}{ }^{90} \mathrm{Y} \\
{ }^{177} \mathrm{Lu}\end{array}$ & $26 \mathrm{~m}$ & - & $14.1 \mathrm{~m}$ & - \\
\hline
\end{tabular}

"Studies with $\leq 3$ patients with LNET or Grade 3 neuroendocrine carcinomas were excluded. Abbreviations: LNET = Lung neuroendocrine tumour, NET $=$ Neuroendocrine Tumour, $\mathrm{N} / \mathrm{E}=$ not evaluable, $\mathrm{ORR}=$ overall response rate, $\mathrm{OS}=$ overall survival, $\mathrm{TTP}=$ time to progression.

incidence of persistant haematologic dysfunction, and $2.9 \%$ incidence of hematopoietic neoplasms, among 274 patients with GEP NETs who had received ${ }^{177} \mathrm{Lu}$-dotatate [41]. A large single institution restrospective study of 521 patients with NET of various primary sites (1 lung NET) who had received ${ }^{177} \mathrm{Lu}$-dotatate found that therapy-related myeloid neoplasms were an infrequent but serious adverse effect, with an incidence of $4.8 \%$ [42], and poor overall survival. Six and nine patients developed AML and MDS respectively. The haematologic events in our 48 patient cohort is in keeping with the incidence seen in this large study and from the Dutch retrospective study.

The limitations of our study are clear. The case numbers are small as with any rare cancer, and patients were treated at multiple sites and over a time period of nearly 20 years. During this time, the histological classification of lung NET changed [43]. However, all patients had a Ki67 of less than $20 \%$, therefore this remains a report of patients with low to intermediate grade NET. Using the patient's treating physician at each site to 
collect the data was aimed at providing the most accurate assessment given the retrospective nature of the study. Only overall survival was reported, as date of last follow up and death could be ascertained reliably, and progression free survival was omitted as it could not be reported with the appropriate degree of certainty and would not be interpretable. Timing and schedule of response evaluation varied between patients and between sites, and were not uniformly measured with standardised criteria. Similarly, symptom evaluation was based on retrospective review of medical records by the treating physician at each site and no QOL questionnaires were used. Uniform adoption of QOL assessment would be an ideal component of a prospective trial.

The argument remains as to the need and viability of a dedicated prospective study of PRRT in lung NETs. Ongoing PRRT studies with ${ }^{177} \mathrm{Lu}$, that are agnostic of NET primary site and thus include lung NETs, are the phase II LUTHREE trial (NCT03454763 [44]), exploring two different dosing schedules, and the phase II P-PRRT trial (NCT02754297 [45]), which investigates personalised PRRT. The combination of ${ }^{177} \mathrm{Lu}$-dotatate PRRT and everolimus is also being evaluated in lung and GEP-NETs, in a phase I-II trial (NCT03629847 [46]). Global efforts could ensure maximum participation so that enrolment is sufficient to make useful conclusions. Other radionuclides under evaluation include ${ }^{212} \mathrm{~Pb}$ DOTAMTATE (AlphaMedix ${ }^{\mathrm{TM}}$ ) in SSTR positive NETs of all primary sites in a phase I trial (NCT03466216 [47]).

Further data will be forthcoming also from studies of PRRT in patients with SSTR-expressing tumours of histologies other than NET. The randomised phase II LUTHREE trial [44] is inclusive of all SSTR positive tumour types, and is not restricted to NETs. The POLNETS trial [48] is also extending the use of PRRT to paraganglioma and pheochromocytoma, in addition to advanced NETs of any site of origin.

\section{MATERIALS AND METHODS}

All major Australian NET treatment centres were invited to participate. After ethics and institutional governance approval, patients with $\mathrm{TC}$ and $\mathrm{AC}$ who received at least 1 dose of ${ }^{177} \mathrm{Lu}$-dotatate between 1 January 2002 and 30 June 2019 were identified from clinical records. Patients with grade 3 tumours or large cell neuroendocrine carcinoma were excluded, as were radionuclides other than ${ }^{177} \mathrm{Lu}$-dotatate. All patients received a renoprotective amino acid infusion prior to intravenous administration of the radiopharmaceutical, using a standard single day protocol [49]. Data was obtained from review of medical records by the treating physician or team member at each site: Monash Health (Victoria), St George and Royal North Shore Hospitals (New South Wales), Royal Brisbane and Women's Hospital (Queensland), The Queen Elizabeth Hospital
(South Australia) and Fiona Stanley Hospital (Western Australia). De-identified data was compiled centrally and queries were referred back to the local site.

\section{Definitions}

Histology was coded as assigned at time of diagnosis. Where classification as either AC or TC was not documented, histopathology was reviewed at the relevant site. Clinical records at or closest to the time of first PRRT were used to source: presence of symptoms, sites of disease (from structural and functional imaging) and a single chromogranin A value. The rationale for treatment was categorised at that time point into: progressive disease, symptom control, or both. Each administration of PRRT was counted as one treatment dose. The first course of PRRT generally comprised two to four sequential treatment doses. Subsequent courses of PRRT were recorded as another line of systemic therapy.

Outcomes related to the initial PRRT course were measured. Overall survival (OS) was measured from the date of delivery of first PRRT until death from any cause. Disease response was based on review by the patient's treating physician of all contemporaneous notes, radiology reports and correspondence, as the retrospective nature of the study did not allow for control and verification of imaging-based outcome measures. Symptom benefit was also based on review of medical records and QOL questionnaires were not used. Toxicity was graded by Common Terminology Criteria for Adverse Events (CTCAE) criteria (version 4.0) [50]. Adverse events included toxicity were summed from all PRRT administrations.

\section{CONCLUSIONS}

This retrospective study contributes to the growing body of evidence evaluating PRRT in lung NET. In the real world, ${ }^{177} \mathrm{Lu}$-dotatate appears to be a relatively safe and effective option for patients with this rare cancer. It is hoped that the many remaining questions are answered by randomised clinical trials or studies using novel designs such as registry trials in the future.

\section{Abbreviations}

${ }^{177} \mathrm{Lu}:{ }^{177}$ Lutetium; 90Y: ${ }^{90}$ Yttrium; AC: atypical carcinoid; AJCC: American Joint Committee on Cancer; AML: acute myeloid leukemia; CTCAE: Common Terminology Criteria for Adverse Events; DLT: dose limiting toxicity; GEP: gastroenteropancreatic; LNET: lung neuroendocrine tumour; MDS: myelodysplastic syndrome; MTD: maximum tolerated dose; NCCN: National Comprehensive Cancer Network; NEC: neuroendocrine carcinoma; NEN: neuroendocrine neoplasm; NET: neuroendocrine tumour; N/E: not 
evaluable; ORR: overall response rate; PD: progressive disease; PFS: progression free survival; PR: partial response; PRRT: peptide receptor radionuclide therapy; QOL: quality of life; SD: stable disease; TC: typical carcinoid; TTP: time to progression; ULN: upper limit of normal; WHO: World Health Organisation.

\section{Author contributions}

All authors contributed to the writing of the manuscript.

\section{ACKNOWLEDGMENTS}

We would like to acknowledge Erika Hosking, St. George Hospital, Sydney, Australia, for her assistance with data collection.

\section{CONFLICTS OF INTEREST}

LE Lim has nothing to disclose; DL Chan has received honoraria and travel support from Novartis and Ipsen Pharma Inc, outside the submitted work; D Thomas has nothing to declare; YT Du has nothing to disclose; $G$ Tincknell has nothing to disclose; A Kuchel has nothing to declare; A Davis has nothing to disclose; DL Bailey has nothing to disclose; $\mathrm{N}$ Pavlakis is on the advisory board and received honoraria from Bristol-Myers Squibb, MSD, Merck-KgA, Boehringer Ingelheim, Astra Zeneca, Roche, Bayer, Novartis, Merck-Serono, Pfizer, Takeda, Ipsen Pharma Inc, research funding from Bayer, Pfizer Pharma Inc, travel funding from Boehringer Ingelheim, BristolMyers Squibb, Roche Pharma Inc, outside the submitted work; G Cehic has nothing to disclose; W Macdonald has nothing to disclose; D Wyld has nothing to disclose; E Segelov has an advisory role for Ipsen, MSD, Athenex Pharma Inc, research funding from Clinical Genomics (Inst), honoraria and travel support from Amgen, Roche Pharma Inc, outside the submitted work.

\section{FUNDING}

No funding was received for the design, data collecton and analysis for this study.

\section{REFERENCES}

1. Hallet J, Law CH, Cukier M, Saskin R, Liu N, Singh S. Exploring the rising incidence of neuroendocrine tumors: a population-based analysis of epidemiology, metastatic presentation, and outcomes. Cancer. 2015; 121:589-97. https://doi.org/10.1002/cncr.29099. [PubMed]

2. Cai B, Broder MS, Chang E, Burk C, Grzegorzewski KJ, Neary MP. PS01.23: Epidemiology of Neuroendocrine Tumors (NET) of the Lung in the US: Analysis of 2
Large Insurance Claims Databases. J Thorac Oncol. 2016; 11:S282-83. https://doi.org/10.1016/j.jtho.2016.09.058.

3. Taal BG, Visser O. Epidemiology of neuroendocrine tumours. Neuroendocrinology. 2004; 80:3-7. https://doi. org/10.1159/000080731. [PubMed]

4. Caplin ME, Baudin E, Ferolla P, Filosso P, Garcia-Yuste M, Lim E, Oberg K, Pelosi G, Perren A, Rossi RE, Travis WD, Bartsch D, Capdevila J, et al, and ENETS consensus conference participants. Pulmonary neuroendocrine (carcinoid) tumors: European Neuroendocrine Tumor Society expert consensus and recommendations for best practice for typical and atypical pulmonary carcinoids. Ann Oncol. 2015; 26:160420. https://doi.org/10.1093/annonc/mdv041. [PubMed]

5. Wyld D, Wan MH, Moore J, Dunn N, Youl P. Epidemiological trends of neuroendocrine tumours over three decades in Queensland, Australia. Cancer Epidemiol. 2019; 63:101598. https://doi.org/10.1016/j.canep.2019.101598. [PubMed]

6. Travis WD, Brambilla E, Nicholson AG, Yatabe Y, Austin JH, Beasley MB, Chirieac LR, Dacic S, Duhig E, Flieder DB, Geisinger K, Hirsch FR, Ishikawa Y, et al, and WHO Panel. The 2015 World Health Organization Classification of Lung Tumors: Impact of Genetic, Clinical and Radiologic Advances Since the 2004 Classification. J Thorac Oncol. 2015; 10:1243-60. https://doi.org/10.1097/ JTO.0000000000000630. [PubMed]

7. Pelosi G, Sonzogni A, Harari S, Albini A, Bresaola E, Marchio C, Massa F, Righi L, Gatti G, Papanikolaou N, Vijayvergia N, Calabrese F, Papotti M. Classification of pulmonary neuroendocrine tumors: new insights. Transl Lung Cancer Res. 2017; 6:513-29. https://doi.org/10.21037/ tlcr.2017.09.04. [PubMed]

8. Edge SB, Compton CC. The American Joint Committee on Cancer: the 7th edition of the AJCC cancer staging manual and the future of TNM. Ann Surg Oncol. 2010; 17:1471-74. https://doi.org/10.1245/s10434-010-0985-4. [PubMed]

9. Dasari A, Shen C, Halperin D, Zhao B, Zhou S, Xu Y, Shih T, Yao JC. Trends in the Incidence, Prevalence, and Survival Outcomes in Patients With Neuroendocrine Tumors in the United States. JAMA Oncol. 2017; 3:1335-42. https://doi. org/10.1001/jamaoncol.2017.0589. [PubMed]

10. Torniai M, Scortichini L, Tronconi F, Rubini C, Morgese F, Rinaldi S, Mazzanti P, Berardi R. Systemic treatment for lung carcinoids: from bench to bedside. Clin Transl Med. 2019; 8:22. https://doi.org/10.1186/s40169-019-0238-5. [PubMed]

11. Tsoukalas N, Baxevanos P, Aravantinou-Fatorou E, Tolia M, Galanopoulos M, Tsapakidis K, Kyrgias G, Toumpanakis C, Kaltsas G. Advances on systemic treatment for lung neuroendocrine neoplasms. Ann Transl Med. 2018; 6:146. https://doi.org/10.21037/atm.2018.04.03. [PubMed]

12. Ferolla P, Brizzi MP, Meyer T, Mansoor W, Mazieres J, Do Cao C, Léna H, Berruti A, Damiano V, Buikhuisen W, Grønbæk H, Lombard-Bohas C, Grohé C, et al. Efficacy and safety of long-acting pasireotide or everolimus alone or in combination in patients with advanced carcinoids of the lung and thymus (LUNA): an open-label, multicentre, randomised, 
phase 2 trial. The Lancet Oncol. 2017; 18:1652-64. https:// doi.org/10.1016/S1470-2045(17)30681-2. [PubMed]

13. Yao JC, Fazio N, Singh S, Buzzoni R, Carnaghi C, Wolin E, Tomasek J, Raderer M, Lahner H, Voi M, Pacaud LB, Rouyrre N, Sachs C, et al, and RAD001 in Advanced Neuroendocrine Tumours, Fourth Trial (RADIANT-4) Study Group. Everolimus for the treatment of advanced, non-functional neuroendocrine tumours of the lung or gastrointestinal tract (RADIANT-4): a randomised, placebocontrolled, phase 3 study. Lancet. 2016; 387:968-77. https://doi.org/10.1016/S0140-6736(15)00817-X. [PubMed]

14. Fazio N, Buzzoni R, Delle Fave G, Tesselaar ME, Wolin E, Van Cutsem E, Tomassetti P, Strosberg J, Voi M, Bubuteishvili-Pacaud L, Ridolfi A, Herbst F, Tomasek J, et al. Everolimus in advanced, progressive, well-differentiated, non-functional neuroendocrine tumors: RADIANT-4 lung subgroup analysis. Cancer Sci. 2018; 109:174-81. https:// doi.org/10.1111/cas.13427. [PubMed]

15. Strosberg J, El-Haddad G, Wolin E, Hendifar A, Yao J, Chasen B, Mittra E, Kunz PL, Kulke MH, Jacene H, Bushnell D, O'Dorisio TM, Baum RP, et al, and NETTER-1 Trial Investigators. Phase 3 Trial of 177Lu-Dotatate for Midgut Neuroendocrine Tumors. N Engl J Med. 2017; 376:125-35. https://doi.org/10.1056/NEJMoa1607427. [PubMed]

16. Strosberg JR, Wolin EM, Chasen BA, Kulke MH, Bushnell DL, Caplin ME, Baum RP, Hobday TJ, Hendifar AE, Lopera Sierra M, Oberg KE, Ruszniewski PB, Krenning E. First update on overall survival, progression-free survival, and health-related time-to-deterioration quality of life from the NETTER-1 study: 177Lu-Dotatate vs. high dose octreotide in progressive midgut neuroendocrine tumors. J Clin Oncol. 2018; 36:4099. https://doi.org/10.1200/ JCO.2018.36.15 suppl.4099.

17. Strosberg J, Wolin E, Chasen B, Kulke M, Bushnell D, Caplin M, Baum RP, Kunz P, Hobday T, Hendifar A, Oberg K, Sierra ML, Thevenet T, et al, and NETTER-1 Study Group. Health-Related Quality of Life in Patients With Progressive Midgut Neuroendocrine Tumors Treated With 177Lu-Dotatate in the Phase III NETTER-1 Trial. J Clin Oncol. 2018; 36:2578-84. https://doi.org/10.1200/ JCO.2018.78.5865. [PubMed]

18. Papamichail DG, Exadaktylou PE, Chatzipavlidou VD. [Neuroendocrine tumors: Peptide receptors radionuclide therapy (PRRT)]. [Article in Greek] Hell J Nucl Med. 2016; 19:75-82. [PubMed]

19. Kanakis G, Grimelius L, Spathis A, Tringidou R, Rassidakis GZ, Öberg K, Kaltsas G, Tsolakis AV. Expression of Somatostatin Receptors 1-5 and Dopamine Receptor 2 in Lung Carcinoids: Implications for a Therapeutic Role. Neuroendocrinology. 2015; 101:211-22. https://doi. org/10.1159/000381061. [PubMed]

20. Ianniello A, Sansovini M, Severi S, Nicolini S, Grana CM, Massri K, Bongiovanni A, Antonuzzo L, Di Iorio V, Sarnelli A, Caroli P, Monti M, Scarpi E, et al. Peptide receptor radionuclide therapy with (177)Lu-DOTATATE in advanced bronchial carcinoids: prognostic role of thyroid transcription factor 1 and (18)F-FDG PET. Eur J Nucl Med Mol Imaging. 2016; 43:1040-6. https://doi.org/10.1007/ s00259-015-3262-8. [PubMed]

21. Parghane RV, Talole S, Prabhash K, Basu S. Clinical Response Profile of Metastatic/Advanced Pulmonary Neuroendocrine Tumors to Peptide Receptor Radionuclide Therapy with 177Lu-DOTATATE. Clin Nucl Med. 2017; 42:428-35. https://doi.org/10.1097/rlu.0000000000001639. [PubMed]

22. Sabet A, Haug AR, Eiden C, Auernhammer CJ, Simon B, Bartenstein P, Biersack HJ, Ezziddin S. Efficacy of peptide receptor radionuclide therapy with (177)Lu-octreotate in metastatic pulmonary neuroendocrine tumors: a dual-centre analysis. Am J Nucl Med Mol Imaging. 2017; 7:74-83. [PubMed]

23. Ezziddin S, Attassi M, Yong-Hing CJ, Ahmadzadehfar H, Willinek W, Grunwald F, Guhlke S, Biersack HJ, Sabet A. Predictors of long-term outcome in patients with welldifferentiated gastroenteropancreatic neuroendocrine tumors after peptide receptor radionuclide therapy with 177Lu-octreotate. J Nucl Med. 2014; 55:183-90. https:// doi.org/10.2967/jnumed.113.125336. [PubMed]

24. Mariniello A, Bodei L, Tinelli C, Baio SM, Gilardi L, Colandrea M, Papi S, Valmadre G, Fazio N, Galetta D, Paganelli G, Grana CM. Long-term results of PRRT in advanced bronchopulmonary carcinoid. Eur J Nucl Med Mol Imaging. 2016; 43:441-52. https://doi.org/10.1007/ s00259-015-3190-7. [PubMed]

25. Pavel M, O'Toole D, Costa F, Capdevila J, Gross D, Kianmanesh R, Krenning E, Knigge U, Salazar R, Pape UF, Öberg K, and Vienna Consensus Conference participants. ENETS Consensus Guidelines Update for the Management of Distant Metastatic Disease of Intestinal, Pancreatic, Bronchial Neuroendocrine Neoplasms (NEN) and NEN of Unknown Primary Site. Neuroendocrinology. 2016; 103:172-85. https://doi.org/10.1159/000443167. [PubMed]

26. Hope TA, Bergsland EK, Bozkurt MF, Graham M, Heaney AP, Herrmann K, Howe JR, Kulke MH, Kunz PL, Mailman J, May L, Metz DC, Millo C, et al. Appropriate Use Criteria for Somatostatin Receptor PET Imaging in Neuroendocrine Tumors. J Nucl Med. 2018; 59:66-74. https://doi. org/10.2967/jnumed.117.202275. [PubMed]

27. Segelov E, Bergsland E, Card C, Hope T, Kunz P, Laidley D, Lawrence B, Leyden S, Michael M, Modahl L, Myrehaug $\mathrm{S}$, Padda S, Pommier R, et al. The commonwealth neuroendocrine tumour collaboration (CommNETs) and North American neuroendocrine tumor society (NANETS) endorsement and update of European neuroendocrine tumor society (ENETS) best practice consensus for lung neuroendocrine tumors (LNET). Ann Oncol. 2018; 29:viii473. https://doi.org/10.1093/annonc/mdy293.015.

28. Shah MH, Goldner WS, Halfdanarson TR, Bergsland E, Berlin JD, Halperin D, Chan J, Kulke MH, Benson AB, 
Blaszkowsky LS, Eads J, Engstrom PF, Fanta P, et al. NCCN Guidelines Insights: Neuroendocrine and Adrenal Tumors, Version 2.2018. J Natl Compr Canc Netw. 2018; 16:693-702. https://doi.org/10.6004/jncen.2018.0056. [PubMed]

29. National Comprehensive Cancer Network. Neuroendocrine and Adrenal Tumors. NCCN Guidelines. 2019. https://www. nccn.org/professionals/physician_gls/default.aspx.

30. Singh SB, Card C, Hope T, Kunz P, Ladiley D, Lawrence B, Leyden S, Michael M, Modahl L, Myrehaug S, Padda S, Pommier R, Ramirez R, et al. Pulmonary Neuroendocrine (Carcinoid) Tumors: CommNETs/NANETS Endorsement and Update of the ENETs Best Practice Consensus. J Thorac Oncol. 2018; 13:S575. https://doi.org/10.1016/j. jtho.2018.08.841.

31. Brabander T, van der Zwan WA, Teunissen JJM, Kam BLR, Feelders RA, de Herder WW, van Eijck CHJ, Franssen GJH, Krenning EP, Kwekkeboom DJ. Long-Term Efficacy, Survival, and Safety of [(177)Lu-DOTA(0),Tyr(3)]octreotate in Patients with Gastroenteropancreatic and Bronchial Neuroendocrine Tumors. Clin Cancer Res. 2017; 23:461724. https://doi.org/10.1158/1078-0432.CCR-16-2743. [PubMed]

32. Horsch D, Ezziddin S, Haug A, Gratz KF, Dunkelmann S, Miederer M, Schreckenberger M, Krause BJ, Bengel FM, Bartenstein P, Biersack HJ, Popperl G, Baum RP. Effectiveness and side-effects of peptide receptor radionuclide therapy for neuroendocrine neoplasms in Germany: A multi-institutional registry study with prospective follow-up. Eur J Cancer. 2016; 58:41-51. https://doi.org/10.1016/j.ejca.2016.01.009. [PubMed]

33. Demirci E, Kabasakal L, Toklu T, Ocak M, Sahin OE, Alan-Selcuk N, Araman A. 177Lu-DOTATATE therapy in patients with neuroendocrine tumours including highgrade (WHO G3) neuroendocrine tumours: response to treatment and long-term survival update. Nucl Med Commun. 2018; 39:789-96. https://doi.org/10.1097/ mnm.0000000000000874. [PubMed]

34. van Essen M, Krenning EP, Bakker WH, de Herder WW, van Aken MO, Kwekkeboom DJ. Peptide receptor radionuclide therapy with $177 \mathrm{Lu}$-octreotate in patients with foregut carcinoid tumours of bronchial, gastric and thymic origin. Eur J Nucl Med Mol Imaging. 2007; 34:1219-27. https://doi.org/10.1007/s00259-006-0355-4. [PubMed]

35. Imhof A, Brunner P, Marincek N, Briel M, Schindler C, Rasch H, Macke HR, Rochlitz C, Muller-Brand J, Walter MA. Response, survival, and long-term toxicity after therapy with the radiolabeled somatostatin analogue [90Y-DOTA]-TOC in metastasized neuroendocrine cancers. J Clin Oncol. 2011; 29:2416-23. https://doi.org/10.1200/ jco.2010.33.7873. [PubMed]

36. Villard L, Romer A, Marincek N, Brunner P, Koller MT, Schindler C, Ng QKT, Mäcke HR, Müller-Brand J, Rochlitz C, Briel M, Walter MA. Cohort Study of SomatostatinBased Radiopeptide Therapy With [90Y-DOTA]-TOC
Versus [90Y-DOTA]-TOC Plus [177Lu-DOTA]-TOC in Neuroendocrine Cancers. J Clin Oncol. 2012; 30:1100-6. https://doi.org/10.1200/jco.2011.37.2151. [ PubMed]

37. Garske-Román U, Sandström M, Fröss Baron K, Lundin L, Hellman P, Welin S, Johansson S, Khan T, Lundqvist H, Eriksson B, Sundin A, Granberg D. Prospective observational study of 177Lu-DOTA-octreotate therapy in 200 patients with advanced metastasized neuroendocrine tumours (NETs): feasibility and impact of a dosimetryguided study protocol on outcome and toxicity. Eur $\mathrm{J}$ Nucl Med Mol Imaging. 2018; 45:970-88. https://doi. org/10.1007/s00259-018-3945-z. [PubMed]

38. Baum RP, Kulkarni HR, Singh A, Kaemmerer D, Mueller D, Prasad V, Hommann M, Robiller FC, Niepsch K, Franz H, Jochems A, Lambin P, Horsch D. Results and adverse events of personalized peptide receptor radionuclide therapy with (90)Yttrium and (177)Lutetium in 1048 patients with neuroendocrine neoplasms. Oncotarget. 2018; 9:16932-50. https://doi.org/10.18632/oncotarget.24524. [PubMed]

39. Sharma N, Naraev BG, Engelman EG, Zimmerman MB, Bushnell DL Jr, O’Dorisio TM, O’Dorisio MS, Menda Y, Müller-Brand J, Howe JR, Halfdanarson TR. Peptide Receptor Radionuclide Therapy Outcomes in a North American Cohort With Metastatic Well-Differentiated Neuroendocrine Tumors. Pancreas. 2017; 46:151-6. https:// doi.org/10.1097/MPA.0000000000000734. [PubMed]

40. Koffas A, Popat R, Demetriou G, Quigley AM, Navalkissoor S, Caplin M, Toumpanakis C. 1059 Effect of Lutetium-177 Dota Octreotate Peptide Receptor Radionuclide Therapy in Patients With Advanced Neuroendocrine Tumors and Carcinoid Syndrome Refractory to Somatostatin Analogues. Gastroenterology. 2016; 150:S208. https://doi.org/10.1016/ S0016-5085(16)30774-0.

41. Bergsma $H$, van Lom $K$, Raaijmakers $M$, Konijnenberg M, Kam B, Teunissen JJM, de Herder WW, Krenning EP, Kwekkeboom DJ. Persistent Hematologic Dysfunction after Peptide Receptor Radionuclide Therapy with (177) Lu-DOTATATE: Incidence, Course, and Predicting Factors in Patients with Gastroenteropancreatic Neuroendocrine Tumors. J Nucl Med. 2018; 59:452-8. https://doi. org/10.2967/jnumed.117.189712. [PubMed]

42. Goncalves I, Burbury K, Michael M, Iravani A, Ravi Kumar AS, Akhurst T, Tiong IS, Blombery P, Hofman MS, Westerman D, Hicks RJ, Kong G. Characteristics and outcomes of therapy-related myeloid neoplasms after peptide receptor radionuclide/chemoradionuclide therapy (PRRT/PRCRT) for metastatic neuroendocrine neoplasia: a single-institution series. Eur J Nucl Med Mol Imaging. 2019; 46:1902-10. https://doi.org/10.1007/s00259-019-04389-2. [PubMed]

43. Rindi G, Klimstra DS, Abedi-Ardekani B, Asa SL, Bosman FT, Brambilla E, Busam KJ, de Krijger RR, Dietel M, El-Naggar AK, Fernandez-Cuesta L, Klöppel G, McCluggage WG, et al. A common classification framework for neuroendocrine neoplasms: an International Agency for Research on Cancer (IARC) and World Health Organization (WHO) expert 
consensus proposal. Mod Pathol. 2018; 31:1770-86. https:// doi.org/10.1038/s41379-018-0110-y. [PubMed]

44. Istituto Scientifico Romagnolo per lo Studio e la cura dei Tumori. Optimizing the Interval Between Cycles of PRRT With 177lu-dotatate in sstr2 Positive Tumors. https:// clinicaltrials.gov/ct2/show/NCT03454763.

45. CHU de Quebec-Universite Laval. Personalized PRRT of Neuroendocrine Tumors. https://clinicaltrials.gov/ct2/show/ NCT02754297.

46. King Faisal Specialist Hospital \& Research Center. Treatment of Neuroendocrine Tumors (NETs) With Combination of Everolimus and Radiolabeled Somatostatin Analogue. https://clinicaltrials.gov/ct2/show/NCT03629847.

47. Radiomedix, Inc. Phase 1 Study of AlphaMedix ${ }^{\text {TM }}$ in Adult Subjects With SSTR (+) NET. https://clinicaltrials.gov/ct2/ show/NCT03466216.

48. Cwikla JB. Peptide Receptor Radionuclide Therapy in the Treatment of Advanced, Non-resectable and/or
Symptomatic Tumors With SSTR Overexpression. https:// clinicaltrials.gov/ct2/show/NCT04029428.

49. Bodei L, Mueller-Brand J, Baum RP, Pavel ME, Hörsch D, O'Dorisio MS, O'Dorisio TM, Howe JR, Cremonesi M, Kwekkeboom DJ, Zaknun JJ. The joint IAEA, EANM, and SNMMI practical guidance on peptide receptor radionuclide therapy (PRRNT) in neuroendocrine tumours. Eur J Nucl Med Mol Imaging. 2013; 40:800-16. https://doi. org/10.1007/s00259-012-2330-6. [PubMed]

50. National Cancer Institute. Common Terminology Criteria for Adverse Events (CTCAE) Version 4.0. 2010. https://evs.nci.nih.gov/ftp1/CTCAE/CTCAE 4.03/ CTCAE_4.03_2010-06-14_QuickReference_5x7.pdf. 